\title{
Tropicália: contracultura, moda e comportamento em fins da década de 60
}

\author{
Tropicália: counterculture, fashion \\ and behavior in the late 1960
}

[resumo] 0 presente artigo analisa a contracultura brasileira por meio do Movimento Tropicalista e sua fabricação de sentidos e identidades reverberadas na moda. Sua forma de expressão e diferenciação foi assinalada por uma linguagem universalista, composta por gírias, roupas coloridas, adereços artesanais, barba e cabelos compridos, por exemplo, que ganhou contornos próprios em cada lugar do planeta, revelando o anseio ideológico de ruptura com os padrões estéticos vigentes. A moda mostra as tensões e os debates estabelecidos naqueles anos em torno das aparências e dos comportamentos que tiveram palco no país, fabricando significados para a indumentária, afirmando identidades e resistências dos segmentos juvenis.

\section{palavras-chave}

moda; contracultura; Tropicalismo;

ditadura militar.

[abstract] This article analyzes the brazilian counterculture through the movement Tropicália and manufacture of meanings and identities reverberated in fashion. His form of expression and differentiation was marked by a universalist language composed of slang, colorful clothes, handmade props, beard and long hair, like, earning themselves contours in every place on the planet, revealing the ideological desire to break with the prevailing aesthetic standards. The fashion reveals the tensions and debates established in those years around the appearances and behaviors that had stage in the country, manufacturing meant for clothing, affirming identities and resistance of juvenile segments.

[keywords] fashion; counterculture; tropicalism; military dictatorship. 


\section{Introdução}

0 presente artigo tem como objetivo geral a análise da contracultura ${ }^{1}$ no Brasil, em fins da década de 60 e sua expressão através da moda, interpretando seus símbolos e significados sociais, culturais e políticos. Especificamente, analisaremos os contornos "tropicais" adquiridos da "deglutição antropofágica" oswaldiana $^{2}$ realizados pelos tropicalistas da matriz norte-americana no âmbito ideológico e quais foram suas "expressões" através da linguagem da moda relacionada ao comportamento, tido como "provocativo" de parte da juventude ${ }^{3}$ da época.

Para tanto, abordaremos a contracultura norte-americana a partir de uma perspectiva histórica e a travessia de suas principais ideias no Brasil, representadas inicialmente pelo Movimento Tropicalista, considerado como a face da nascente contracultural brasileira (BUENO, 1979; CAPELLARI, 2007; CYNTRÃO, 2000; DUNN, 2009)4; e também suas experienciações no campo existencial, político e estético por meio da indumentária construída, ressignificando assim, 0 movimento em suas interfaces com a formação de estilos e identidades na sociedade contemporânea.

\section{A contracultura na "América do Sol": o movimento hippie no Tropicalismo}

A vanguarda contra a retaguarda! A loucura contra a burrice! $0 \mathrm{im}$ pacto contra a mediocridade! 0 sexo contra os dogmas! A realidade contra os suplementos! A radicalidade contra o comodismo! Tropicalistas de todo mundo, uni-vos. (BRITO, 1968, p. 3)

Surgido inicialmente na imprensa norte-americana nos anos 1960, o termo contracultura ganhou um espaço de circulação amplo, principalmente porque 0 fenômeno a que se referia com a manifestação do movimento hippie revelava-se a um número crescente de pessoas - estudantes, grupos minoritários e marginalizados da sociedade e intelectuais da chamada Nova Esquerda, entre outros - como um tema obrigatório de discussão.

A contracultura com seu caráter eclético, simultaneamente místico e político, emergiu como resposta crítica diante das ilusões do capitalismo e do rigoroso sistema tecnocrático. Seu caráter político ganhou visibilidade nos Estados Unidos por causa da luta integrada pelos direitos civis dos negros, homossexuais e mulheres, da inserção do jovem enquanto importante ator social, do pacifismo e do pensamento ecológico, entre outras novas proposições que não eram contempladas na chamada política tradicional. Não se tratava de uma luta para substituir a sociedade capitalista pela socialista, ambas industriais e assentadas na tecnocracia, mas questionar os pressupostos da civilização industrial e seu paradigma central: a racionalidade instrumental. A ideia era descentralizar tal paradigma, abrindo-se a outras possibilidades e assumir uma nova prática existencial, sem as amarras e a rigidez da sociedade dos especialistas.

Por meio dos êxtases propiciados pelas drogas e filosofias orientalistas, do rock (como "hino da revolução hormonal" da juventude), da colocação do sexo como proposição social e da formação das comunidades hippies, por exemplo, tentava-se buscar a reintegração da totalidade humana, aspirando a uma volta à natureza e à retribalização. 0 chamado do neotribalismo se daria com os meios comunicacionais de massa, formando a idealizada aldeia global, preconizada por Marshall McLuhan (1977), com o advento tecnológico que marcou a época: a televisão.

As formas de expressão e diferenciação desse grupo que se identificava com a proposta contracultural hippie foram assinaladas comumente por uma linguagem 
universalista caracterizada por gírias, danças, roupas coloridas, adereços artesanais, barba e cabelos compridos (importante símbolo de identificação do "jovem aquariano"5), que ganhou contornos próprios em cada lugar do planeta revelando 0 anseio ideológico de ruptura com os padrões estéticos vigentes.

Desde os anos 1950, com os chamados "rebeldes sem causa", o jovem passou a ser considerado um importante ator social, gerador de mudanças e criador de estilos próprios que o diferenciavam de outros grupos sociais e etários. Nessa época, o jovem se torna consumidor em potencial, pois com a mesada que recebia dos pais, comprava seus "símbolos diferenciadores": discos de rock e roupas, entre outros, disseminados pelos meios comunicacionais, especificamente, o cinema. Filmes a exemplo de 0 selvagem (The Wild One, EUA, 1953) e Juventude transviada (Rebel Without a Cause, EUA, 1955), retratavam os medos, os anseios e as carências que junto a uma indumentária específica, encarnavam a rebeldia da geração com seus "casacos de couro, roupas pretas, topetes e lambretas", embalados no mais genuino "Rock Around the Clock" de Bill Haley and His Comets.

Já as décadas de 60 e 70, como afirma Edgar Morin (1987), foram assinaladas por acontecimentos que romperam com a ideia de linearidade histórica, demarcando uma fase transitória para a nova sensibilidade descentralizada, síncrona e polifônica que emergia e comunicava não mais apenas com as palavras, mas com o corpo - o olhar, o cabelo, as vestes unissex, confortavelmente largas e coloridas. A indumentária, nesse contexto, remetia-se a influências do "passado/presente/ futuro" indo além das ideias de temporalidade e gênero. Segundo astrólogos e futuristas, iniciava-se a Era de Aquarius; para os mais céticos, apenas a chamada pós-modernidade.

Em Aquarius renasce tudo. Deve ser a casa do Renascimento. 0 planeta vai ficar mais exigente, em relação à bomba. Nada de poluição, de Química e mesmo de Física. E não deixar ninguém te botar para baixo. Os jornais serão considerados, todos (sem exceção) como objeto de uso ultrapassado. A linguagem não é mais aquela. Diz com o olho, com o cabelo, com a cor, com o sotaque, com o joint, com a macrobiótica, o sorriso, o incenso e a graça [...] Aquarius já começou... (VICENTE, 1971, p. 9).

Essa nova sensibilidade delineada de forma assistemática pelos movimentos de contracultura no início dos anos 1960, chegou ao Brasil tardiamente, no fim da década, no contexto de recrudescimento da repressão militar, adquirindo "cores locais", principalmente comportamentais e estéticas, incompreendidas por grande parte da população brasileira, por meio do Tropicalismo.

\section{Contracultura, Tropicalismo \&t identidade nacional}

A essência do Tropicalismo era um desejo amoroso de modernidade para o Brasil. Era todo um ponto de vista que estava, e continua reprimido e que naquele momento histórico a gente pôde veicular. Foi um momento de êxtase, de criatividade real e que alimentou e alimenta até hoje este país. Foi talvez o movimento mais moderno do Brasil no sentido de que ele era um movimento ligado a uma civilização contemporânea e de massas, sem ranços, sem compromissos ou peias ideológicas com facções de esquerda, ou de direita. Era a própria inteligência brasileira se manifestando, num momento de consciência, de lucidez e de paixão por esse país. Era também um momento em que uma potencialidade brasileira se apresentou. Porque quando eu falo de Tropicalismo, sempre digo que não é um 
movimento, é a própria arte brasileira. 0 modernismo já era assim. $A$ vocação do Brasil é essa. Essa é a nossa fala. Essa é nossa identidade. Há visões superficiais disso, mas essa vocação brasileira está aí em tudo: nessa garra, nessa paixão, nessa identidade universal do brasileiro. (DUARTE, 2003, p. 138)

Segundo Contier (2003), o Movimento Tropicalista teve duração efêmera comumente, com início datado em setembro de 1967 e término em dezembro de 1968. Contudo, suas repercussões alcançam os dias atuais, seja na arte, na moda, seja no comportamento por meio de seu caráter experimental. 0 professor Jornard Muniz de Britto afirma o aspecto contínuo do movimento:

[...] a Tropicália não se encerrou em 1969. É uma pesquisa contínua que Caetano, Gil, Tom Zé, nunca deixaram de fazer. 0 tropicalismo é se jogar no experimental, transexperimental. É a arte em processo permanente de invenção, sem ter o compromisso com a arte popular nacional. (JORNARD apud CONTENTE, 2013, p. 6)

Suas propostas ganharam visibilidade principalmente com o III Festival de Música da TV Record (1967), o álbum/manifesto Tropicália ou Panis et Circensis (julho de 1968) e o programa na TV Tupi intitulado Divino, Maravilhoso (1969) que divulgou através dos meios de comunicação de massa, as novas formas de ser, sentir e pensar o Brasil.

Um ano após o estouro de "Alegria, Alegria" e "Domingo no Parque", um ano após a sacudilela na música popular brasileira, de que resultaram novas concepções, novos caminhos, somente depois de um ano de discutidos, condenados e elogiados, Caetano Veloso e Gilberto Gil conseguem um programa na televisão. Só anteontem, em "Divino e Maravilhoso" na TV Tupi, o público telespectador, ou a massa média, começa a apreciar mais extensamente, a estética nova que os baianos se propõem comunicar. Só agora, com o programa regular e sistemático, Caetano e Gil tem oportunidade de testar o seu novo comportamento musical. Da aceitação ou não, do consumo ou não, já que eles estão na faixa do produssumo produzir para o consumo, no neologismo criado por Décio Pignatari - depende a sobrevivência do grupo e a validez de suas teses, de sua revolução. (FOLHA DE S. PAULO, 1968, p.3)

0 Tropicalismo foi apreendido pelas alas conservadoras como um verdadeiro perigo para a sociedade em razão de suas ideias libertárias e desagregadoras da família e do sistema, uma moda exótica de viés burguês e uma afronta à cultura nacional, em face do ataque imperialista norte-americano expresso, por exemplo, com a inserção das guitarras elétricas na música popular brasileira e da caracterização visual hippie.

Tanto a direita militar quanto a esquerda ortodoxa consideravam o "desbunde ${ }^{6 "}$ como um movimento "imaturo", subjetivo e individualista. Seus participantes foram rotulados de "meninos de Marcuse", "alienados" e, por fim, "malucos" pela valorização dos processos intuitivos, sensórios e imaginativos. Abaixo, pronunciamentos críticos a respeito do Tropicalismo, retirados de jornais e revistas da época (LONTRA, 2000, p. 32): 
Dinah Silveira de Queiroz, 1968 (QUEIROZ apud LONTRA, 2000, p.32):

[...]Esta Tropicália, que anda por aí, importada da Europa, não é nada para nós. Não se aperceberam de uma realidade dramática: estão caricaturizando a sua própria condição.

Chico Ribeiro, 1968 (RIBEIRO apud LONTRA, 2000, p.32):

0 que é válido, o que é essencial para o pensamento velosiano, é que leve as circunstâncias cerebrais o mesmo aspecto de desordem capilar que o Caetano Veloso apresenta fora da cachola.

Manchete de O Estado de S. Paulo, 30/04/68, p. 14:

\section{Tropicália não convence.}

Um novo Tropicalismo: Tropicalismo é um negócio que a gente sente que está deste lado, mas está do lado de lá.

Augusto Boal, no artigo Que pensa você da arte de esquerda? caracterizou o Tropicalismo como:

[...] romântico: agride o predicado, mas não o sujeito; homeopático, por endossar o objeto da crítica; inarticulado; tímido e gentil, pois teria satisfeito apenas os burgueses e um fenômeno de importação - cópia dos Beatles. Enfim, o Tropicalismo se caracterizaria por completa ausência de lucidez. (BOAL apud LONTRA, 2000, p. 32)

A despeito das críticas, Celso Favaretto afirma em Tropicália, alegoria, alegria (1996) que o Tropicalismo surgiu como um discurso inovador, propondo uma discussão, substancialmente distinta das anteriores, como tática cultural, proposta ideológica e relacionamento com o público. Era uma posição definitivamente artística e musical. Rearticulando uma linha de tradição abandonada desde o início do século e retomando as pesquisas sobre o Modernismo, principalmente a antropofagia oswaldiana, rompeu com o discurso explicitamente político para concentrar-se em uma atitude primitiva que, pondo de lado a realidade nacional, via 0 Brasil sob a ótica revolucionária da visão cultural. Confundindo o nivel em que se situavam as discussões culturais, o Tropicalismo deu uma resposta desconcertante à questão das relações entre arte e política.

Segundo Bueno (1979), a incompreensão das propostas tropicalistas, não impediu suas manifestações de resistência perante o cerceamento da liberdade, que obteve visibilidade em shows improvisados, espetáculos teatrais, filmes super-8, publicações (que raramente chegavam a ter uma grande circulação e cuja existência era efêmera) e uma indumentária que "brincava" de forma oswaldiana, antropofágica, com os símbolos nacionais e estrangeiros, do presente e do passado e com os valores sacralizados da cultura ocidental.

0 poeta Haroldo de Campos enfatiza:

[...] a tarefa do movimento tropicalista foi a de assimilar sob a espécie brasileira a experiência estrangeira e reinventá-la em termos nossos, com qualidades ineludiveis que dariam ao produto resultante um caráter autônomo e lhe confeririam, em princípio, a possibilidade de passar a funcionar por sua vez, num confronto internacional, como produto de exportação. (CAMPOS apud VELOSO, 1997, p. 247) 
A marca comum aos tropicalistas era a diversificada teia de referências culturais que absorviam de forma intuitiva (não era uma apropriação ou "deglutição" sistemática e racional de elementos, geradora de uma síntese) e que criou uma arte brasileira diferente das vertentes nacionalistas de até então.

\section{Antropofagia tropicalista \&t carnavalização}

[...] 0 Manifesto Antropófago propõe inverter essa lógica colonial. Ver a Europa com os olhos da criança que viu o rei nu. Inventar o olhar brasileiro. Usar o automóvel para descobrir a poesia da Mata Atlântica. Usar os potenciais da modernidade para sacudir a dependência cultural. Ler Freud para entender a feijoada. Dançar o Congo para responder a Kant. Tupi or not Tupi that is the question. (SEVCENKO, 1998, p. 24)

Invenção e Saque. Originalidade na combinação dos elementos. Os indígenas se apropriando dos temas dos conquistadores. (SALOMÃO,1972, pp.19-20).

"Ver com os olhos livres a realidade". Por meio dessa máxima oswaldiana, os tropicalistas construíram suas ideias confrontando a seriedade acadêmica e a política tradicional institucionalizada, revelando o anseio libertário e a tendência à carnavalização. Ou seja, segundo Oswald de Andrade, deveriamos "ver e viver" aquilo que somos: "uma mistura de vatapás e chaminés, xarope bromil, abacaxi e coca-cola" (CALAD0,1997, p.175). Essa visão do mundo diversificada e complexa encontra no Movimento Tropicalista a base de agregação das formas da modernidade, ressignificando as diversas informações universais na construção da ideia de país pluridentitário.

A antropofagia, no sentido da absorção cultural a que o grupo ansiava, inspirava-se nas vivências de volta a um passado tribal, o chamado "Matriarcado de Pindorama ${ }^{7 "}$ - país das palmeiras - gênese das pulsões primárias e "dionisíacas". A ideia, porém, não era a de retroceder na história, mas sim a de defender a interação dessas pulsões primárias e dionisiacas com os avanços da cultura e da sociedade contemporânea.

A antropofagia cultural foi o processo utilizado para a "deglutição" das influências colocadas comumente como antagônicas: "o nacional versus o internacional", "o rural versus o urbano", "o industrial versus o artesanal", "o irracional versus o racional", "o pais subdesenvolvido, mas industrializado" (grifo nosso). Como produto dessa deglutição cultural, novas formas culturais foram construídas oferecendo respostas críticas aos ditames acadêmicos instituídos sobre diversas questões, entre elas, a de identidade nacional, fomentadora de grandes embates.

0 manifesto intitulado Cruzada tropicalista, publicado no jornal carioca Última Hora pelo jornalista e letrista Nelson Mota (em matéria de 5 de fevereiro de 1968), ilustrou com uma foto de Vicente Celestino, que algo de extraordinário estava prestes a acontecer na vida cultural do pais:

[...] 0 filme Bonnie and Clyde faz atualmente um tremendo sucesso na Europa e sua influência estendeu-se à moda, à música, à decoração, às comidas, aos hábitos. Os anos 30 revivem em força total. Baseados neste sucesso e também no atual universo pop - com o 
psicodelismo morrendo e novas tendências surgindo -, um grupo de cineastas, jornalistas, músicos e intelectuais resolveu fundar um movimento brasileiro, mas com possibilidades de se transformar em escala mundial: o Tropicalismo. Assumir completamente tudo que a vida nos trópicos pode dar, sem preconceitos de ordem estética, sem cogitar de cafonice ou mau gosto, apenas vivendo a tropicalidade e o novo universo que ela encerra, ainda desconhecido. (MOTTA, 1968, pp. 5-6)

A filosofia de assumir tudo o que a vida nos trópicos podia oferecer sem preconceitos estéticos, expressando uma assimilação do "senso comum", representado como arte genuína, deu-se com o uso de chavões, provérbios e até cantadas da época, tais como: "Verde assim; que dirá madura"; "Esta é a nora que mamãe queria", "Arte moderna é pra enganar os trouxas"; entre outras. As festividades comerciais, colocadas como religiosas, também eram consideradas datas de extrema importância: Natal, Ano Novo, Dia das Mães, entre outras, deveriam ser comemoradas "em infindáveis piqueniques onde estarão sempre presentes: laranjas, bananas, fritadas de vagem e garrafas de tubaína. Abaixo os jantares e coquetéis. Viva o piquenique!" (CALADO, 1997, p.178).

A ironia funcionava como um estopim na guerrilha ideológica estendendo-se tanto para os militares, quanto para os militantes ortodoxos de esquerda. Os tropicalistas foram vaiados nos festivais de música, presos sem motivos concretos pela polícia e ridicularizados pela família brasileira, que não aceitava a caricatura do Brasil apresentada.

A ridicularização e a perseguição se davam geralmente de forma simplista em resposta à provocação ocasionada pela caracterização visual e pelo comportamento desses artistas que se relacionavam e se assemelhavam ideologicamente (com suas devidas proporções e contextualizações) com o movimento hippie norte-americano.

Com a ditadura fechando o cerco gradativamente com os Atos Institucionais, os tropicalistas Caetano e Gil foram presos "sem motivos concretos". Da cela da prisão, junto com Paulo Francis, Ferreira Gullar e Antônio Callado, entre outros intelectuais, Caetano foi levado a um soldado em uma sala da Vila Militar. Como Caetano narra em seu livro Verdade tropical (1997), esse soldado, excepcionalmente, intelectualizado e politizado, ponderou-lhe quanto o rock e a música pop poderiam funcionar como elementos desagregadores da familia e quanto o Movimento Tropicalista provocava os militares que até então perseguiam com mais voracidade os militantes políticos da esquerda:

[...] Com essa capacidade de pulverizar a realidade, esse modo de tratar fragmentariamente os costumes e valores morais, vocês podem causar mais danos à estabilidade de nossa sociedade do que à esquerda. Essa é a verdadeira subversão. (VELOSO, 1997, p. 18)

0 caráter subversivo de exposição do quadro de fragmentação da "verdade absoluta" brasileira entrelaçava-se com os novos dados internacionais pautados na experiência hippie.

[...] o tropicalismo, além de ter atuado sem ufanismo e sem demagogia populista; além de ter incorporado o tom parodístico e bem-humorado, crítico e dessacralizador, de Oswald de Andrade e do legado antropofágico do Modernismo; além de ter transferido a criação poética revolucionária para as letras de música; além de ter antropofagicamente, colocado em confronto o legado anterior da música popular brasileira com a música pop internacional; além disso, tudo estava assumindo, nos palcos e nos meios de massa, 
atitudes e comportamentos [...] linguagens novas, muito mais próximas da agitação juvenil internacional do que qualquer outro movimento, dentro ou fora do Brasil (BUENO,1979, p. 25)

0 Movimento Tropicalista incorporou novas linguagens expressas por meio da arte, do comportamento diferenciado, provocativo e da moda - modo de identificação e diferenciação do referido grupo.

\section{Antimoda tropicalista \&t experienciações no campo existencial, político e estético}

[...] Ao observar o Tropicalismo com os olhos da moda, a complexidade de suas práticas se revela com a ambiguidade e violência simbólica que são duas de suas características. 0 tropicalismo foi, entre outras coisas, uma moda e suas obras e histórias extraem sua força do contato com esta. Mas, correlativamente, também foi um movimento que pôs a moda em tensão com a arte e a cultura. Suas composições musicais extraíram os objetos de seu contexto e os puseram diante do peso da transitoriedade da moda, convertendo-os em relíquias (a religião é substituída pela moda como horizonte de sentido de alegoria). (AGUILAR, 2005)

A moda que reverberou das experienciações tropicalistas, na esteira dos movimentos de contracultura, nos traz elementos importantes para o entendimento dos processos de identificação e diferenciação de grupo, levando à interpretação do comportamento social e da relação entre gostos e roupas.

A aparência e a indumentária expressam o sentimento de pertencimento a uma tribo, estreitando os laços entre os jovens de todo o mundo, diferenciando-os de outros segmentos sociais em termos comportamentais, políticos e estéticos. Segundo Pereira (2016), os jovens, mais sensiveis e abertos a questões sociais de mudança, supervalorizam elementos como aparência e costume no processo de identificação e pertencimento a uma tribo. Maffesoli (1998) caracteriza o sentimento tribal como: uma sensação comum de pertencimento (designado como estética), o laço coletivo de empatia (ética) e o resíduo que fundamenta o "estar junto" (o costume).

A contracultura (nacional e estrangeira), mesmo se rebelando contra o sistema estabelecido foi absonvida pelo capitalismo com mecanismos de massificação com o consumo de seus principais símbolos transformados ao "sabor do tempo e do vil metal", em mercadorias.

A prática cultural desruptiva ancorada em uma estética da bricolagem, do excesso e da descontinuidade observada, segundo Connor (1996), sustenta-se sob a égide do desafio a um conjunto de normas culturais dominantes ou oficiais e comprometidas que, por sua vez, anulam a possibilidade da diversidade. Segundo Cidreira (2008), o que permite e cria as condições da própria política da diversidade que defende a prática cultural de resistência, é muito mais um afrouxamento da pressão de uniformidade autoritária e uma expansão e diversificação de normas oficiais do que uma súbita tomada de consciência revolucionária ou de uma postura crítica.

A verdade do Tropicalismo está no consumo e, com relação a este, não Ihe interessa distanciar-se e denunciá-lo (o que seria fazer música de protesto), mas sim mergulhar nele. Frente ao cinismo do músico de protesto que deve submeter-se ao mercado musical, ao mesmo tempo que o rejeita, o cinismo dos tropicalistas é o preço que devem 
pagar para experimentar com seus próprios corpos no cenário dos meios de comunicação de massa da sociedade de consumo - seus corpos como encarnação da moda e da mercadoria. (AGUILAR, Gonzalo. Antimoda - extraido de Poesia Concreta Brasileira, Edusp, 2005. Tropicália: um projeto de Ana de Oliveira. Sao Paulo, 2017. Leituras Complementares. Disponivel em: http://tropicalia.com.br/ leituras-complementares/antimoda-2 Acesso em: 14 abr. 2016.)

0 hipongo tropicalista, chamado também de bicho-grilo, cabeludo e desbundado incorporou uma moda relacionada a um estilo de vida que ia além das polarizações ideológicas, dos maniqueísmos e das dualidades, utilizando-se dos aparatos da sociedade de consumo, a exemplo dos meios comunicacionais de massa, em prol da expansão e da diversificação dos conteúdos e informações.

\footnotetext{
[...] Rubert de Ventos, pesquisador da área da Estética assinala que a moda se converte em estilo, na medida em que responde a necessidade de exprimir uma nova perspectiva ou conteúdo da realidade cultural e social. As formas de caracterização visual dos anos 60 e 70 refletem uma concepção de vida, um estilo relacionado à cultura pop e a filosofia hippie. (CIDREIRA, 2008, p. 39)
}

Em fins dos anos 1960, no Brasil, a aparência e a indumentária, relacionadas especificamente ao Tropicalismo, constituiram-se em uma antimoda, no sentido de romper estética e moralmente com padrões, considerados ultrapassados. Expressaram por meio da arte, as novas formas e linguagens e os novos conteúdos, utilizando-se de metáforas e alegorias de suas produções artísticas, seus corpos e vestes.

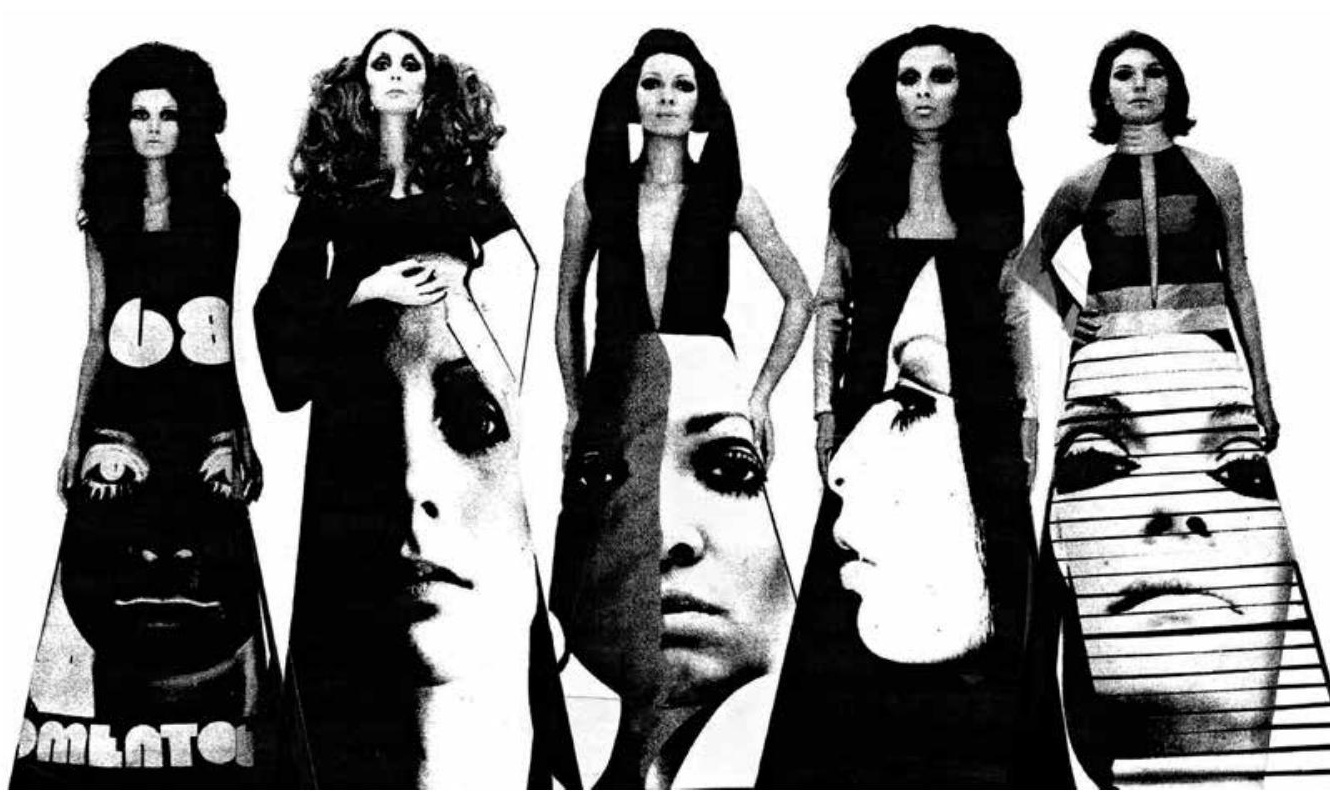

Figura 1 - Cartaz do desfile Tropicália, apresentado em 1968, na FENIT.

Fonte: Acervo Rhodia.

A moda tropicalista advinha de diversificadas referências e do experimentalismo caraterístico da época percebidos nas músicas, nos happen$n^{n i g s^{8}}$, nas indumentárias e nas capas dos discos, entre outros. A capa do álbum/manifesto Tropicália ou Panis et Circensis (1968), por exemplo, mostra uma família classe média existencialmente entediada ("as pessoas na sala 
de jantar, acostumadas a nascer e morrer"), um retrato obtuso e crítico da instituição primeira da sociedade. A guitarra empunhada pelos Os Mutantes simboliza a influência do rock (tida comumente como uma afronta imperialista $\left.{ }^{10}\right)$; a boina utilizada por Torquato Neto, uma breve remissão à identidade latino-americana e à indumentária do líder guerrilheiro Che Guevara; Rogério Duprat tomando café em um penico nos leva ao surrealismo de Duchamp, entre muitas interpretações resultantes do rico diálogo semiótico que trava com o público.

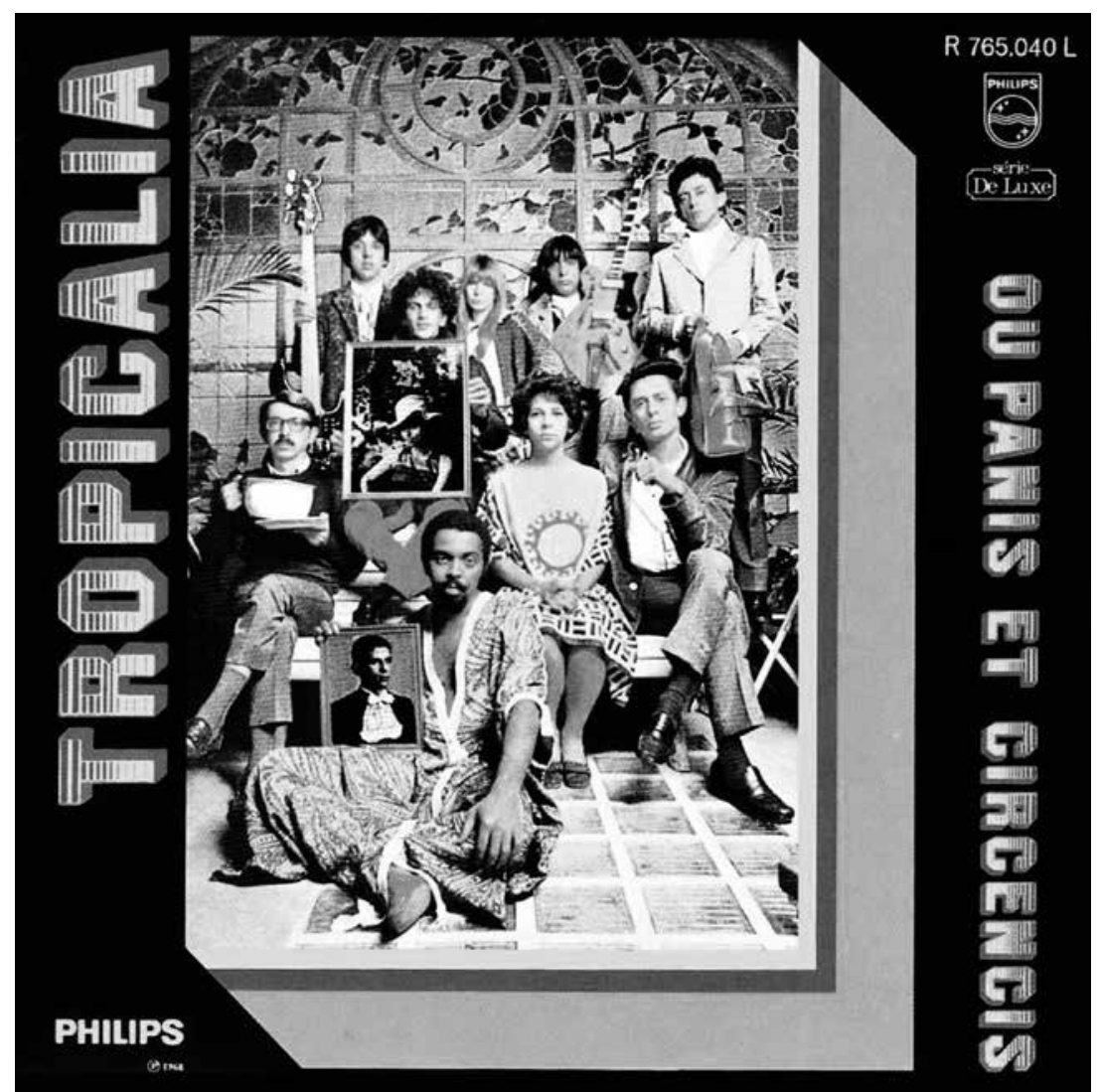

Figura 2 - Capa do álbum Tropicália ou Panis et Circencis (1968).

Acervo pessoal.

As vestes e a aparência em geral foram os meios enunciadores da mensagem - parafraseando a premissa mcluhaniana de que "o meio é a mensagem" (MCLUHAN, 1996) -, um prolongamento do corpo, comunicadores das novas propostas. A imagem dos tropicalistas que escandalizava o público geral era tão importante quanto os shows, as declarações públicas dos artistas e as capas dos discos, por exemplo. A começar pelos cabelos compridos e despenteados que ganhou uma matéria especial escrita por Jorge Mautner na edição de número 1 da revista alternativa brasileira Rolling Stone (1972)"11, porta voz do movimento contracultural no Brasil, sobre a importância dos "cabelos grandes" no Ocidente e sua discriminação pelas alas conservadoras da sociedade:

A massa, o povo, não estranha cabelos compridos nem com eles se escandaliza como faz a classe média em seu ritual puritano. Os pescadores, os caipiras, os vaqueiros nordestinos, os 
caiçaras, os habitantes mágicos das cidades mágicas como Moxotó, reagem ao cabeludo dentro da naturalidade que a visão mítica e fantástica da vida Ihes deu. Quem vive com lemanjá, D. Dorotéia, despachos, obás, escolas de samba, nações de maracatu, etc não há de se espantar nem horrorizar com os cabelos compridos. Para este incrivel e maravilhoso povo, o jovem cabeludo, pode ser um peregrino santo cumprindo uma promessa para sua mãe, ou então simplesmente, pertence a uma outra tribo, porque há tantas...E de mais a mais, a reação contra o cabelo comprido é uma reação de repressão sexual clara e definida. A massa que vive no delírio e na maravilha não é puritana, apenas inocentemente antropofágica (MAUTNER,1972, p. 10).

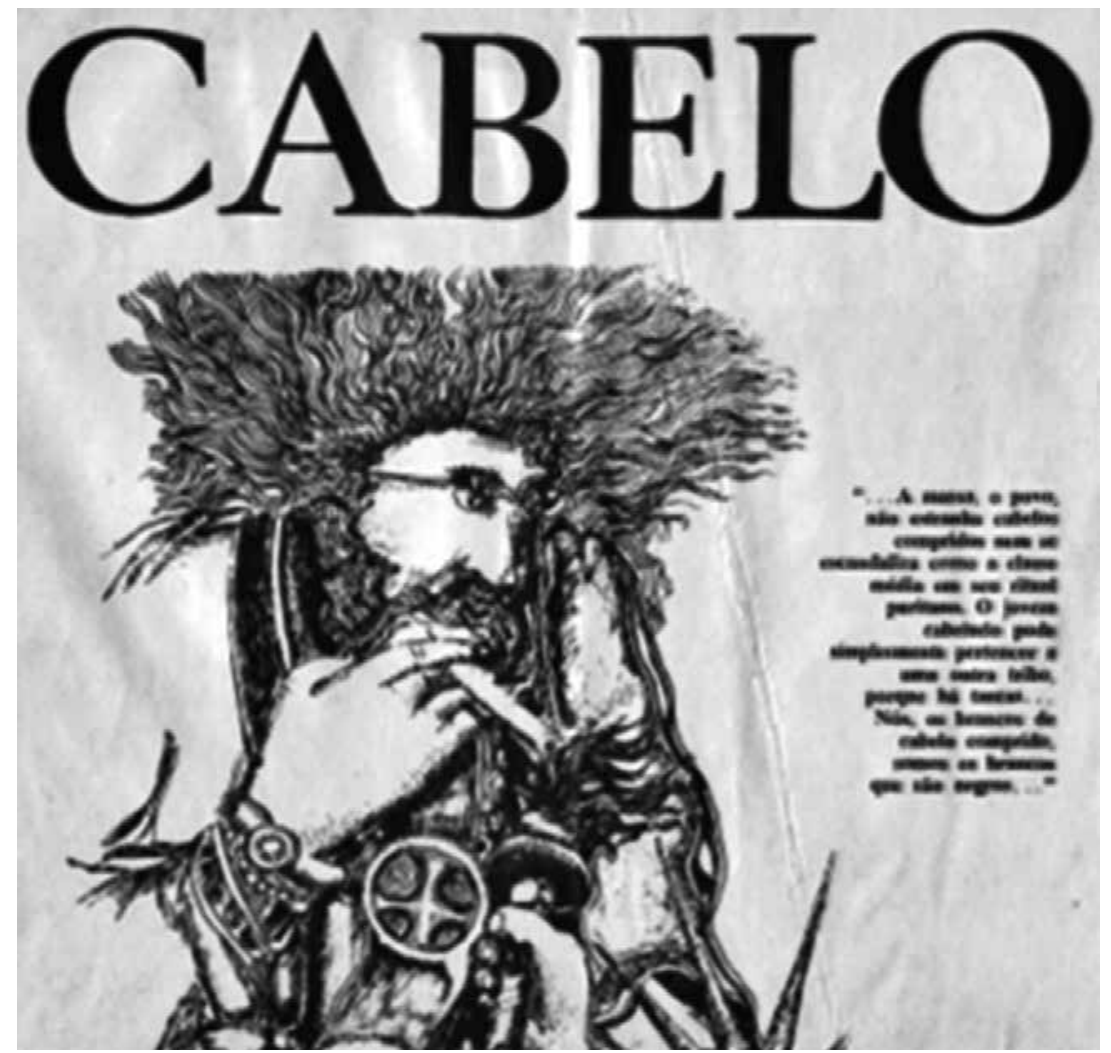

Figura 3 - Matéria de Jorge Mautner para a revista Rolling Stone (versão brasileira), intitulada Cabelo. Fevereiro de 1972, n. 1, p. 10.

Acervo pessoal.

Os cabelos compridos dos jovens junto às cores berrantes das vestes, relacionavam-se com o neotribalismo e o psicodelismo, este último como forma de vida e proposta de desterritorialização, na criação e percepção diferenciadas e transmutadoras da chamada "realidade objetiva"12. A asserção desse estilo de vida configurado na moda atingiu um público amplo com o decorrer do tempo (desde jovens que se identificavam com a proposta tropicalista até aqueles que não a compreendiam, mas faziam uso em seus momentos de lazer, por exemplo, de uma calça jeans desbotada ou de peças confortáveis e coloridas inspiradas no movimento). 


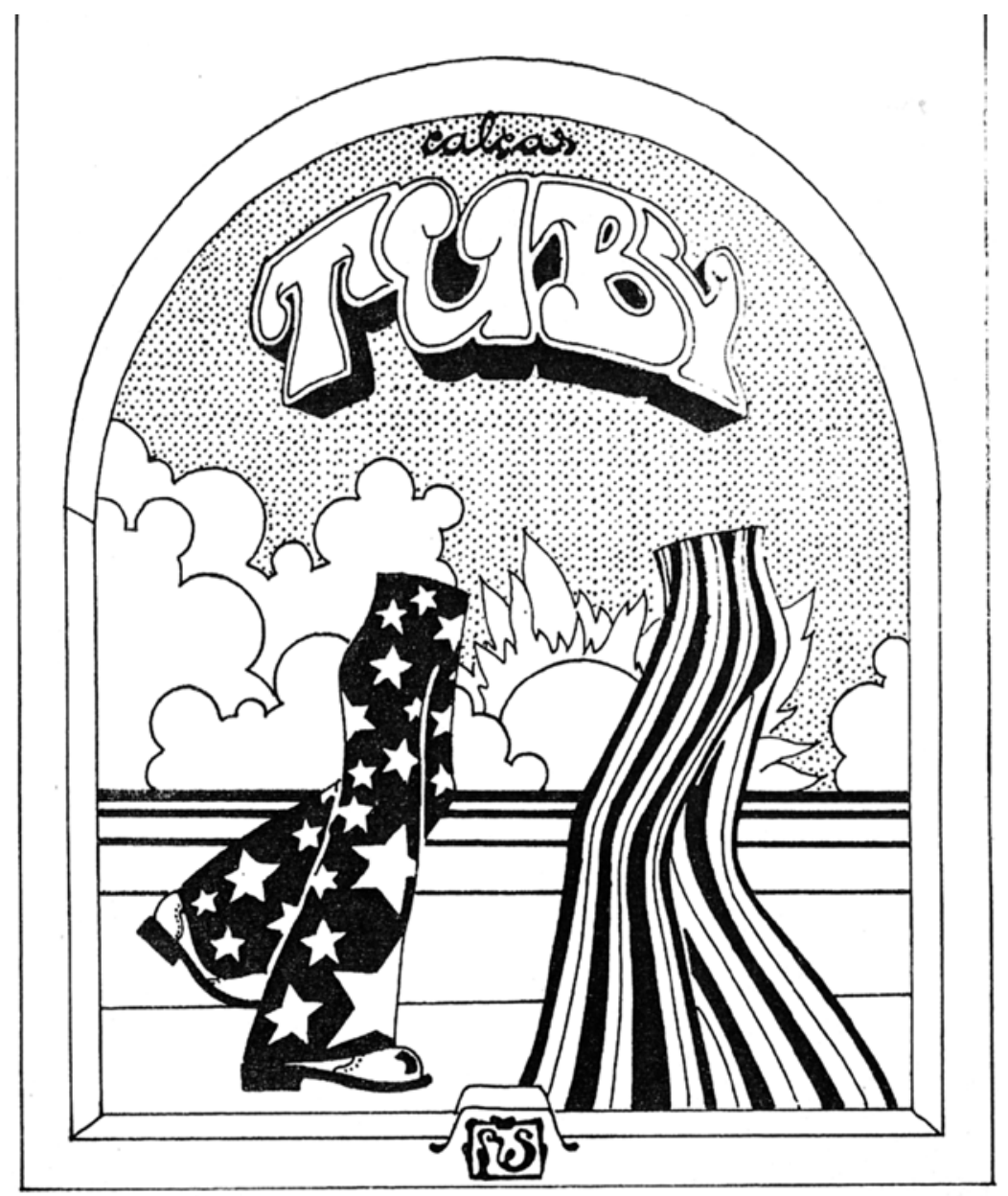

\section{PRUDENTE DE MORANS 1292237 JPADENATROO}

Figura 4 - Propaganda das calças Tuby veiculada na revista Rolling Stone (versão brasileira), de 1972.

Acervo pessoal.

Roupas indianas (e a orientalização do 0cidente) elaboradas de forma artesanal, calças jeans de boca de sino (a moda unissex na esteira da revolução sexual em curso), símbolos brasileiros bordados e utilizados como adereços (colocando a questão nacionalista em voga), vestidos de noivas, ternos antigos e fardas (remetendo à crítica às instituições, como a família, a escola e todo poder estabelecido), em meio a toda indumentária que caracterizou a liberdade de expressão e a volta ao natural, foram algumas das premissas tropicalistas na moda. 


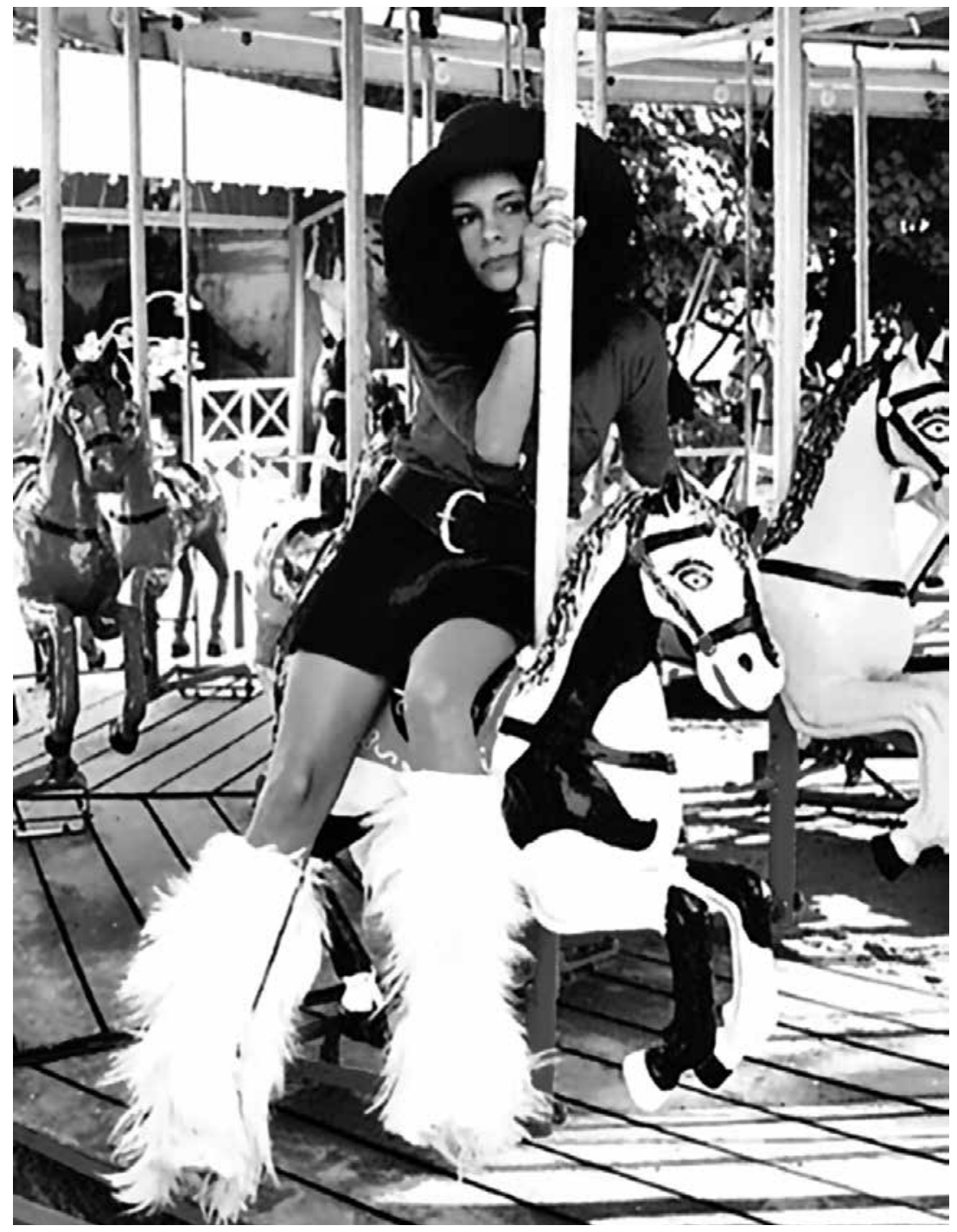

Figura 5 - Gal Costa, uma das protagonistas e veiculadoras da exótica moda tropicalista, na revista comportamental A Cigarra (1970).

Fonte: <http://musacabocla.blogspot.com.br/2009/01/revista-cigarra-1970.html> Acesso em: 7 jul. de 2016.

Gilda Chataignier (2010) definiu como uma "moda tropicalista", o exótico, a começar pelos cabelos longos, cacheados ou afros (quanto mais natural seu aspecto, melhor) até os pés, com sandálias plataformas de madeira ou cortiça. 0 aspecto lúdico do Tropicalismo foi também incorporado por meio da moda fantasia que poderia ser vislumbrada nos estilos hippie, cigano, indiano, camponês, marinheiro e japonês entre outros, assim como nos figurinos das atrizes famosas da época que eram muitas vezes tomados e reinventados. 0 flower power norte-americano foi incorporado nas estampas com flores pequenas e médias, nos cabelos, em broches, faixas, camisas e vestidos. 0 grafismo nas vestes levou o olhar a dimensões sensoriais e extrassensoriais, sendo uma tendência na moda e na "vida".

Maria Claudia Bonadio (2010) afirma que devido ao processo de crescente urbanização percebida no fim dos anos 1960 e durante a década de 70, consolidou-se uma indústria voltada para o vestuário que propiciou às confecções especializadas elaborar produtos de boa qualidade (seguindo tendências ditadas internacionalmente), associadas a outro fenômeno surgido também nessa época: as butiques. Entre as incipientes butiques voltadas ao público jovem e tropicalista, destacou-se a Dromedário Elegante de Regina Helena Boni, aberta em 1968, na Rua Bela Cintra (São Paulo). 0 trabalho de Boni deu visibilidade aos trajes e acessórios tropi- 
calistas, criando a identidade visual do movimento a partir das composições das músicas e suas influências que iam desde a carnavalização proposta pela poética oswaldiana, passando pelo surrealismo e pelo kitsch até o mundo eletrônico da TV.

Sobre a referida moda jovem e provocadora, a jornalista, fotógrafa e designer gráfica Marisa Alvarez Lima (que participou ativamente do Movimento Tropicalista e das manifestações de arte-antiarte, cultura e contracultura nos anos 1960 e 1970), afirma que:

A moda é jovem, louca, embora tenha descoberto um imenso potencial em elementos do passado que, assimilados, segundo a receita tropicalista, ressurgem fascinantes, vivos. [...] é preciso ser artista ou se sentir como se fosse, para se vestir no Dromedário Elegante. Cada um com sua ideia e a butique com a ideia total. Do muito avançado ao muito antigo e passeando pelo surpreendente. moda é escandaloso, tudo é um jogo divertido. No parque de diversões eles se misturam: um pouco do conto de fadas, alguma coisa de inocente, o riso puro. (LIMA, Marisa Alvarez. Moda mutante: extraído da Marginália - na Idade da Pedrada, RioArte, 1996. Tropicália: um projeto de Ana de Oliveira. São Paulo,2007. Leituras Complementares Disponivel em http:// tropicalia.com.br/ leituras-complementares/moda-mutante Acesso em: 7 jul. 2016. )

Desse "jogo divertido" como afirma Lima (1996), nasce a antimoda tropicalista que reverberou nas ruas, nas butiques, nos corpos, nos costumes e nas infinitas possibilidades de se expressar os novos tempos. A chamada nova consciência foi relacionada ao mundo eletrônico, às tribos juvenis e à contracultura brasileira: "moda mutante, ODromedário Elegante. Vestir? Ou despir? A moda está na moda? Quem fez a moda? Você! Panis et Circenses!" (LIMA, Marisa Alvarez. Moda mutante: extraído da Marginália - na Idade da Pedrada, RioArte, 1996. Tropicália: um projeto de Ana de Oliveira. São Paulo,2007. Leituras Complementares Disponivel em http:// tropicalia. com.br/leituras-complementares/moda-mutante Acesso em: 7 jul. 2016. ).

\section{Considerações finais}

Buscou-se neste artigo apresentar os primeiros resultados da pesquisa "Impressões e Expressões do Tropicalismo na moda", analisando o significado da contracultura norte-americana, suas reverberações por meio do Movimento Tropicalista e suas experienciações no campo existencial, da estética e da política não tradicional.

A contracultura foi um importante movimento de cunho juvenil que colocou em questão a sociedade ocidental, capitalista e tecnocrática. A difusão dessas ideias no Brasil comportou soluções diferentes, ao esbarrar em realidades sociais, políticas e culturais complexas e singulares da matriz norte-americana (BUENO, 1979). Inicialmente, tais ideias puderam ser vistas com o Movimento Tropicalista, que deflagrou o processo de renovação e revolução dentro da arte brasileira, em contexto de recrudescimento da ditadura militar e de polarização ideológica.

Apesar da afirmação dos críticos de que o movimento era "colonizado" e estaria repetindo as experiências estrangeiras e incorporando-as no Brasil com atraso e diluidas, "macaqueando" sua matriz, os tropicalistas ao contrário incorporaram e digeriram esses dados antropofagicamente (BUENO,1979). Assumia-se com o movimento, todo o atraso, a cafonice, o subdesenvolvimento, entre outros elementos nacionais transformando-os em arte genuinamente brasileira relacionando-a com aquilo que acontecia no exterior e também com referências do pas- 
sado e do presente, do clássico e do popular, mostrando que o país não poderia se definir identitariamente de forma simples, genérica e una. A questão comportamental advinda da contracultura norte-americana foi de suma importância para a produção de uma resistência e uma diferenciação de grupo composto por uma minoria de jovens no Brasil. 0 movimento, pouco compreendido por grande parte da população brasileira, provocava reações de desagrado e reprovações. A linguagem utilizada pelos tropicalistas não era de fácil entendimento para a maior parte da população e incomodava devido à dimensão política que causava em razão das críticas e reflexões que propunha contra as instituições, a repressão militar, a ortodoxia da esquerda (incentivando a mudança não apenas do discurso, mas também da linguagem) e a ideia linear de identidade nacional brasileira. 0 Movimento Tropicalista fez uma intervenção fulgaz que, contudo, abriu caminho para uma descentralização cultural importante de uma série de experiências artísticas que aconteceram pós-1968, rotuladas de contraculturais e marginais (BUENO, 1979).

A identidade de grupo no Tropicalismo foi construída por meio da aparência e da indumentária que sintetizava suas premissas, ou seja, da moda, percebida não mais de forma simplista, como um mero diferenciador das classes sociais e econômicas.

A força da imagem, da aparência e da indumentária são elementos importantes na solidificação de grupos específicos, constituindo-se em emblemas e símbolos significativos das transformações que os jovens das décadas de 60 e 70 almejavam.

A moda hippie persiste, contudo, com outra conotação. Segundo Cidreira (2008), o consumidor que adquire produtos relacionados aos símbolos de contestação/rebeldia, de alguma forma, ganha uma identificação com o movimento de outrora. Porém, a roupa só adquire significado mediante as circunstâncias nas quais é usada. 0 vigor expressivo da indumentária só ganha sentido no ato de vestir (CIDREIRA, 2008) e no devir.

Segundo Rolland Barthes (2005), a moda tem traços mundanos que são infinitos, inumeráveis e abstratos. A contracultura, por sua vez, oferece também um horizonte de possibilidades, pois se trata de um processo dinâmico que persiste atualmente, de forma diferenciada, pelos nichos contraculturais que com seu hedonismo, transgridem o "estabelecido", conjugando a estética pós-moderna.

Em meio aos escombros da pós-modernidade, da complexidade das relações sociais, políticas e culturais, a moda contracultural por um lado se afirma como um produto a ser consumido; por outro, rompe com a hierarquia e a uniformidade em busca da individualidade e da originalidade reinventando e estetizando a existência, reagindo à liquidez da sociedade contemporânea. Como afirmou o artista Hélio Oiticica: "Vestir é um ato mágico". (LIMA, Marisa Alvarez. Moda mutante: extraído da Marginália - na Idade da Pedrada, RioArte, 1996. Tropicália: um projeto de Ana de Oliveira. São Paulo,2007. Leituras Complementares Disponivel em http:// tropicalia.com.br/leituras-complementares/moda-mutante Acesso em: 7 jul. 2016.) 


\section{NOTAS}

[1] De forma geral, entende-se historicamente como contracultura, o movimento social juvenil de caráter internacionalista relacionado às décadas de 60 e 70 que teve como mote a critica à cultura dominante. Ganhou visibilidade e alcance no Brasil em fins da década de 60, inicialmente com o Tropicalismo e posteriormente, com a incorporação do caráter underground nas artes, na imprensa alternativa, na produção literária independente e na estética marginal, expressões de resistência frente ao momento de repressão ditatorial e de ressignificação do caráter identitário nacional. Conceitualmente e de forma perene, a contracultura floresce "sempre e onde quer que alguns membros de uma sociedade escolham estilos de vida, expressões artísticas e formas de pensamento e comportamento que incorporam o antigo axioma segundo o qual, a única verdadeira constante é a propria mudança. Sua marca é a fluidez de formas e estruturas, a perturbadora velocidade e flexibilidade com que surge, sofre mutação, se transforma em outra e desaparece" (GOFFMAN; JOY, 2007, p. 9).

${ }^{[2]}$ Refiro-me à antropofagia cultural postulada pelo poeta modernista Oswald de Andrade (1890-1954) na construção de uma arte brasileira moderna que propunha a "deglutição" de estilos e modelos nacionais e internacionais, do presente e do passado, apresentando uma proposta de reinvenção cultural, inspirada nas vivências de volta a um passado tribal junto aos avanços da cultura e da sociedade contemporânea (PAIANO, 1996). 0 conceito oswaldiano de antropofagia cultural foi retomado pelo Movimento Tropicalista nos anos 60, promovendo uma renovação estética, abrindo novas possibilidades para a produção artística e cultural e inserindo novas formas de ser, sentir e pensar o Brasil (BARROS, 2000).

[3] Segundo Theodore Roszak, em sua obra A contracultura: reflexões sobre a sociedade tecnocrática e a oposição juvenil (1972), apesar dos movimentos alternativos ganharem dimensões internacionais, nem todos os jovens estavam na condição de oposição, "talvez apenas uma minoria de universitários. Entretanto, nenhuma posição analítica, senão a que vê uma minoria militante de jovens dissidentes em choque com a política apática de consenso e coalizão de seus pais burgueses, parece explicar as grandes perturbações políticas da época" (ROSZACK, 1972, p.16). No Brasil, segundo Sirkis (SIRKIS apud GARCIA, 1999, p.112), mediante a repressão militar, parte da juventude se trifurcou; uma parte alinhou-se com o discurso da esquerda tradicional, entrando para a guerrilha; outra parte deu prosseguimento aos planos dos pais e da sociedade da "ordem e do progresso": e houve ainda um novo discurso postulado por artistas e intelectuais que reverberou em círculos restritos, atingindo pequena parte da classe média brasileira. Esse discurso se relacionou à contracultura e aos ecos dessa em terras brasileiras.

4] Há vasto estudo sobre a relação do Tropicalismo com a contracultura norte-americana (apontando a singularidade de suas manifestacõos em contextos específicos sociais, políticos e culturais) perscrutando seus caminhos e descaminhos no Brasil. Os pesquisadores referenciados, mesmo com fundamentações teóricas e metodológicas diferenciadas, postulam que a nascente contracultura brasileira adquiriu de sua matriz norteamericana, nuanças estéticas e comportamentais percebidas inicialmente, por meio do Tropicalismo.

5] Os jovens ganharam várias denominações nas décadas de 60 e 70: "mutantes", "desbundados", "hipongos", "jovens da Era de Aquarius", entre outras, com acepções de predestinação à transformação e assim, renovação da sociedade em todos os âmbitos.

[6] Segundo Gonçalves (2008,p.39), "parte dos integrantes da geração anos 1970 - o que não exclui integrantes de outras gerações -, não reconheciam mais na militância política um ideal de vida a ser seguido e, em convergência com a liberalidade proposta pelos movimentos de contracultura, adotaram o desbunde como signo de rebeldia e descrença em relação aos projetos revolucionários e, de certo modo, também à ordem vigente".

${ }^{[7]}$ Para o poeta Oswald de Andrade, a sugestão do retorno ao Matriarcado de Pindorama referia-se à busca de uma nova perspectiva para as raizes genuínas da raça e da cultura brasileira, inseridas em uma atualização crítica do panorama artístico, em consonância com os novos recursos, e não um simples retorno reducionista ao suposto purismo do folclore e aos elementos telúricos da tradição nacional, fechados, intocáveis, objetivos então defendidos pelos engajados politicamente (COSTA, 2011, p.3).

${ }^{[8]} 0$ termo happening significa "acontecimento" e consiste em espetáculos nos quais há apresentação musical, visual e estética, buscando uma interação constante com o público (BARROS, 2000, p.86).

[9] Trecho da letra da música Panis et Circenses, gravada pelos Mutantes, em 1968. Faixa do álbum-manifesto tropicalista: Tropicália ou Panis et Circenses.

${ }^{[10]}$ Cabe ressaltar que artistas relacionados ao nacional/popular repudiavam o rock dentro da música popular brasileira e assim, promoveram em São Paulo, no dia 17 de julho de 1967, a "passeata contra as guitarras elétricas" (CALAD0, 1997, p. 109).

${ }^{[11]}$ A revista Rolling Stone em sua versão brasileira foi lançada por Luiz Carlos Maciel, em fevereiro de 1972, com o mesmo título da matriz americana, tendo como intuito não apenas divulgar informações acerca dos grandes astros da música pop internacional e nacional, como também discutir literatura, cinema, filosofia, comportamento, sexualidade e drogas, entre outros assuntos em voga. Foi uma publicação inicialmente mensal, voltada para o rock e o contexto da contracultura que passou, posteriormente, a ter periodicidade semanal, persistindo até o $36^{\circ}$. número, lançado em 1973. Pode-se afirmar que foi uma das precursoras do gênero no país, ganhando visibilidade na época (o que não era tão comum, tratando-se de imprensa alternativa), e abriu caminho para outras publicações que ambicionavam tratar de assuntos não veiculados pela imprensa oficial. Contudo, não obteve o mesmo êxito mercadológico da matriz norte-americana, falindo nos primeiros números.

${ }^{[12]}$ Naquele contexto, a juventude contracultural se adentrou em "reinos fora da história oficial" (seja por meio das drogas alucinógenas, do misticismo profético, das viagens pelas highways do mundo, ou outras), considerando outras realidades que não apenas as dadas como objetivas e racionais.

\section{AGRADECIMENTO}

A Profa. Ivana Guilherme Símili (UEM/La Moda), incentivadora do presente trabalho.

Dedico este artigo à memória de Rogério Duarte (1939-2016), "poeta" do design gráfico, mentor da estética tropicalista 


\section{REFERÊNCIAS}

AGUILAR, Gonzalo. Antimoda - extraído de Poesia Concreta Brasileira, Edusp, 2005. Tropicália: um projeto de Ana de Oliveira. São Paulo. Leituras Complementares. Disponivel em: http://tropicalia.com.br/ leituras-complementares/antimoda-2 Acesso em: 14 abr. 2016.

FOLHA DE S.PAULO. Baianos na TV: BAIANOS NA TV: "Divino, Maravilhoso". São Paulo: 30 out. 1968. Tropicália: um projeto de Ana de Oliveira. São Paulo. Reportagens históricas. Disponível em: http:// tropicalia.com.br/eubioticamente-atraidos/reportagens-historicas/baianos-na-tv-divino-maravilhoso Acesso em: 12 abr. 2016.

BARROS, Patrícia Marcondes de. "Panis et Circenses": a ideia de nacionalidade no Movimento Tropicalista. Londrina: EDUEL, 2000.

BARTHES, Rolland. Imagem e moda. Inéditos. v.3. São Paulo: Martins Fontes, 2005.

BONADIO, Maria Claudia. A produção acadêmica sobre moda na pós- graduação stricto sensu no Brasil (Dossiê). lara - Revista de Moda, Cultura e Arte. v.3, n. 3, p. p. 50 - 146, dez. 2010.

BRITO, Jornard Muniz de. Porque somos e não somos tropicalistas. Jornal do Commércio. Pernambuco, p. 3. abril, 1968.

BUENO, André Luiz de Lima. Contracultura: as utopias em marcha. Rio de Janeiro, 1979. 200f. Dissertação (Mestrado em Letras). Pontifícia Universidade Católica do Rio de Janeiro.

CALADO, Carlos. Tropicália: a história de uma revolução musical. São Paulo: Editora 34, 1997.

CAPELLARI, Marcos Alexandre. 0 discurso da contracultura no Brasil: o Underground através de Luiz Carlos Maciel. São Paulo, 2007. 256p. Tese (Doutorado em História Social). Universidade de São Paulo.

CHANTAIGNER, Gilda. História da moda no Brasil. São Paulo: Estação das Letras e Cores, 2010.

CIDREIRA, Renata Pitombo. A moda nos anos 60/70: comportamento, aparência e estilo. Recôncavos: Revista do Centro de Artes, Humanidades e Letras. vol. 2, n.1, p.35-44, 2008.

. Estilo, moda e Consumo (Por uma poética do precário?). In: V ENCONTRO DE ESTUDOS MULTIDISCIPLINARES EM CULTURA, 2009, Salvador. Anais eletrônico. Salvador: UFBA, 2009, p. 1-12. Disponivel em http://www.cult.ufba.br/enecult2009/19637-4.pdf Acesso em: 20 fev. 2016.

CONNOR, Steven. Cultura pós-moderna: introdução às teorias do contemporâneo. $3^{\mathrm{a}} \mathrm{ed}$. Trad. Adai Ubirajara Sobral e Maria Stela Gonçalves. São Paulo: Edições Loyola, 1996.

CONTENTE, Renato. Manifesto Tropicalista, um senhor de 45 anos. Jornal do Comércio, Pernambuco, abr. 2013, p.6.

CONTIER, Arnaldo Daraya et al. 0 Movimento Tropicalista e a revolução estética. Caderno de PósGraduação em Educação, Arte e História da Cultura. . São Paulo: Editora Mackenzie, v. 3, n.1. pp.135159, 2003.

COSTA, Patricia Anzini da. Pra não dizer que não falei de Antropofagia: a tropical devoração oswaldiana. Darandina Revista Eletrônica. Revista do Programa de Pós-Graduação em Letras (UFJF), v. 4, n. 1, pp. 01-22, 2011.

CYNTRÃO, Sylvia Helena (Org). A forma da festa. Tropicalismo: a explosão e seus estilhaços. Editora da UNB, Brasilia, 2000

DUARTE, Rogério. Tropicaos. 1ª Rio de Janeiro: Azougue Editorial, 2003.

DUARTE, Rogério. Tropicaos. 1ed. Rio de Janeiro: Azougue Editorial, 2003.

DUNN, Christopher. Brutalidade jardim: a Tropicália e o surgimento da contracultura brasileira. São Paulo: Editora UNESP, 2009.

FAVARETTO, Celso. Tropicália, Alegoria, Alegria. São Paulo: Ateliê Editorial, 1996.

GARCIA, Marco Aurélio e VIEIRA, Maria Alice. Rebeldes e contestadores: 1968, Brasil, França e Alemanha. São Paulo: Perseu Abramo, 1999.

GONÇALVES, Daniel José. 0 desbunde como manifestação política: a identidade de gênero na obra de Ana Cristina César. Curitiba, 2008. 126p. Dissertação (Mestrado em Estudos Literários). Universidade Federal do Paraná. 
JOY, Dan; GOFFMAN, Ken. A contracultura através dos tempos. Rio de Janeiro: Edições EDIOURO, 2007.

LIMA, Marisa Alvarez. Moda mutante: extraido da Marginalia - na Idade da Pedrada, RioArte, 1996. Tropicália: um projeto de Ana de Oliveira. Sao Paulo, 2007. Leituras Complementares Disponivel em http:// tropicalia.com.br/leituras-complementares/moda-mutante Acesso em: 7 jul. 2016.

LONTRA, Hilda. Tropicalismo: a explosão e seus estilhaços. In: HELENA, S. (Org). A forma da festa. Brasilia: Editora Universidade de Brasilia, 2000.

MAFFESOLI, Michel. 0 tempo das tribos: o declínio do individualismo nas sociedades de massa. $2^{\mathrm{a}} \mathrm{ed}$. Trad. Maria de Lourdes Menezes. Rio de Janeiro: Forense-Universitária, 1998.

McLUHAN, Marshall. A galáxia de Gutenberg. A formação do homem tipográfico. São Paulo: Ed. Nacional, 1977

1996.

. Os meios de comunicação como extensões do homem. 8a ed. Editora Cultrix

MAUTNER, Jorge. Cabelo. Revista Rolling Stone. Rio de Janeiro n.1, pp. 9-10. fev. 1972.

MORIN, Edgar. Cultura de massas no século XX. Volume 1: Neurose. 3 ed. Rio de Janeiro: Forense Universitária,1987.

MOTTA, Nelson. Cruzada tropicalista. Jornal Última Hora. Rio de Janeiro, pp.5-6. fev. 1968.

PAIANO, Enor. Tropicalismo: bananas ao vento no coração do Brasil. São Paulo: Scipione, 1996.

PEREIRA, Carolina Morgado. Os jovens e a contracultura brasileira. lara - Revista de Moda, Cultura e Arte. São Paulo: Editora SENAC. v.8, n. 2, pp. 7-28. Jan. de 2016.

ROSZAK, Theodore. A contracultura: reflexões sobre a sociedade tecnocrática e a oposição juvenil. Petrópolis: Vozes, 1972.

SALOMÃO, Wally. Me segura que eu vou dar um troço. José Álvaro Editora: 1972.

SEVCENKO, Nicolau. Alegria é a prova dos nove: Hamlet com farofa. Revista Bravo, São Paulo, 1998.pp. 23-24.

Tropicália: um projeto de Ana de Oliveira. São Paulo, 2007. Reportagens históricas. Disponivel em:http:// tropicalia.com.br/eubioticamente-atraidos/reportagens-historicas/baianos-na-tv-divinomaravilhoso Acesso em: 12 abr. 2016.

VELOSO, Caetano. Verdade tropical. São Paulo: Cia das Letras, 1997.

VICENTE, G. Ser criança, namorar, passear. Flor do Mal, Rio de Janeiro. 1ª. Ed., 1971, p.9. 